\title{
Aj atz'aam, "los de la sal". El uso de la sal en la ciudad maya de Calakmul
}

\section{Aj Atz'aam, "The Salt People". The Use of Salt at the Maya City of Calakmul}

\author{
Rogelio Valencia Rivera \\ Investigador independiente
}

\begin{abstract}
Resumen: El presente artículo muestra la existencia del transporte e intercambio de mercancías cuya producción, si es que la había, no podía satisfacer el consumo local, debido al crecimiento poblacional que muchos sitios del área maya sufrieron durante el periodo Clásico Tardío. Si bien existen estudios que hablan acerca del intercambio de artículos empleados por la sociedad maya durante el periodo Clásico, éstos suelen ser sobre todo de objetos utilizados por la élite. En este caso me centraré en el papel de la sal como elemento indicador de la existencia de tal actividad, apoyándome en las evidencias de su uso que aparecen en las pinturas murales de la ciudad maya de Calakmul, donde la presencia del transporte de dicho mineral se debía a la necesidad de su consumo por parte de los pobladores, a la carencia de fuentes locales para su obtención y a la lejanía de los lugares confirmados donde se producía.
\end{abstract}

Palabras clave: sal, intercambio, comerciantes, pinturas murales, Calakmul.

AвSTRACT: This paper shows the existence of the transportation and exchange of goods that could not be produced, or were not even present locally, to satisfy a community's self-consumption, due to an increase in population during the late Classic in the Maya area. Although some studies discuss the exchange of goods in Maya society during the Classic period, they are usually centered on the objects employed by the Maya elites. In this case, I will analyze the role of salt as an indicator of the existence of exchange activities using the evidence available in the mural paintings in the Maya city of Calakmul. The need of the mineral for human consumption, the lack of local sources of the mineral, and the long distance to salt sources, set the stage for exchange travels in order to import it to Calakmul.

KEYwORDs: salt, exchange, merchants, mural paintings, Calakmul. 
RECEPCIÓN: 10 de abril de 2019.

ACEPTACIÓn: 10 de julio de 2019.

DOI: https://doi.org/10.19130/iifl.ecm.55.2020.0001

\section{Introducción}

La sal es la substancia obtenida de la combinación de un átomo de sodio y uno de cloro, los cuales al unirse forman un compuesto denominado cloruro de sodio $(\mathrm{NaCl})$. Es un mineral cristalino, soluble en agua, cuyo color normalmente es blanco, y que posee un sabor característico. La sal es empleada por los humanos para tratar los alimentos con dos fines, darles sabor y ayudar a su conservación (Outram, 2007: 57; Williams, 2010). Esta sustancia es muy difícil de estudiar arqueológicamente ya que, al ser muy soluble, tiende a no dejar residuos y no se puede identificar su consumo en los esqueletos humanos (Outram, 2007: 57). La sal se emplea también para facilitar los procesos de secado que permiten el empleo de otros métodos de preservación de la comida, tales como el escabeche, el ahumado, el curado y la fermentación, especialmente en regiones donde las condiciones de secado no son las ideales; tal secado de los alimentos mediante el empleo de sal se da por un proceso de ósmosis (Shepard, 2000: 54). La sal se puede encontrar en forma sólida en minas que contienen dicho mineral, o disuelta en agua, ya sea en el mar o en lagunas saladas y puede hallarse en casi cualquier parte del mundo, bajo una forma u otra. Si se encuentra disuelta en agua, suele ser obtenida mediante evaporación (Figura 1), ya sea del agua de mar, de lagos salados o de fuentes de salmuera (Outram, 2007: 57).

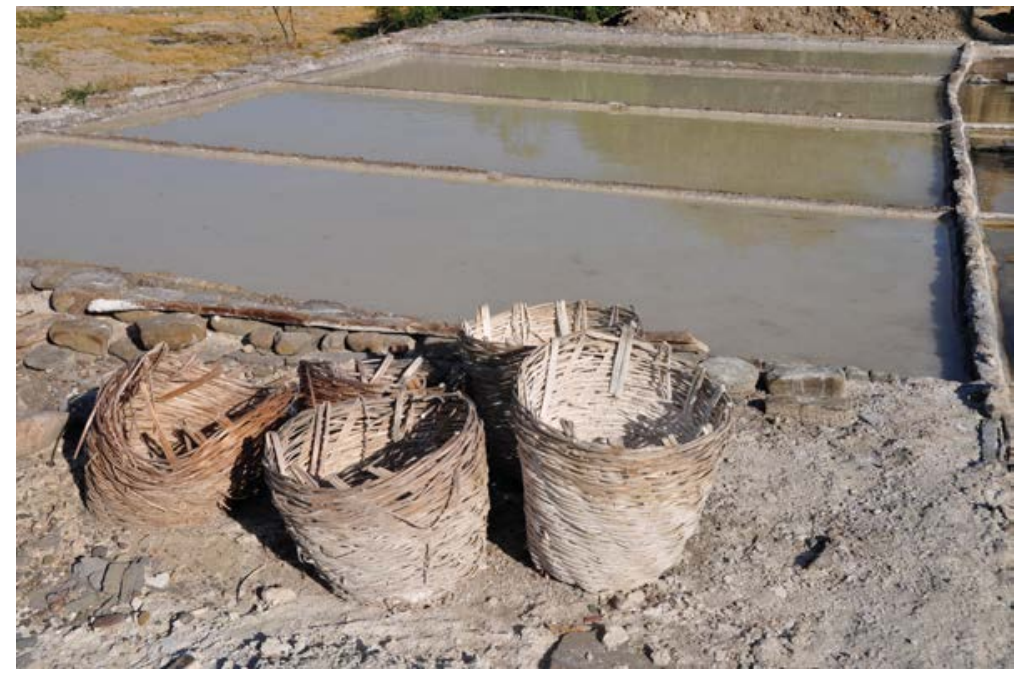

Figura 1. Salina localizada en la reserva de la biósfera de Tehuacán-Cuicatlán donde se puede apreciar el proceso de obtención de sal mediante desecación solar (Fotografía: Rogelio Valencia). 
Las primeras minas de sal se comenzaron a explotar alrededor de la Edad de Bronce. Sabemos por Herodoto que en el siglo v a.C. los babilonios y los egipcios conservaban peces y aves en escabeche. En Inglaterra se comenzó a extraer sal mediante evaporación en la Edad de Hierro, método introducido por los celtas. Este método se siguió empleando hasta después de la llegada de los romanos, quienes dotaron al proceso de salado de los alimentos de un alto grado de perfección, añadiendo especias y hierbas al mismo (Shepard, 2000: 65).

Contamos con evidencia arqueológica procedente de sitios en Veracruz, tales como El Salado (Santley, 2004; Williams, 2010: 184), que durante el Preclásico Temprano (2000-1000 a.C.) se dedicaron a la fabricación de recipientes cerámicos usados con el fin de evaporar sal mediante la intervención del sol (Outram, 2007: 57). En Europa, existen evidencias de la obtención de sal utilizando estos utensilios desde el Neolítico, pero hay mejor información durante las Edades de Bronce y Hierro. Estos recipientes constituyen lo que se denomina como briquetaje, elementos cerámicos elaborados de forma burda para la fabricación de crisoles, cacerolas y pilares. Los pilares sostienen los recipientes sobre una hoguera que facilita la evaporación (Outram, 2007: 57).

Los pueblos que no podían producir u obtener suficiente sal por sus propios medios debían estar preparados para pagar por ella, en ocasiones altos precios. Ello ocurría especialmente en el norte de Europa, donde el pescado y la carne salados eran una parte importante de la dieta. Es así como la sal se convirtió en objeto de un mercadeo intenso y llegó a ser llamada "oro blanco", al que algunos gobernantes impusieron fuertes impuestos. Francia, que tomó el ejemplo de los normandos y éstos de los árabes, empleó impuestos sobre la sal hasta 1790 , durante el mandato de Luis XIV. La palabra moderna "salario" deriva de la ración de sal que los romanos acostumbraban a pagar a los soldados denominada salarium (Shepard, 2000: 65).

Además de ser una forma de dar sabor a la comida, esta sustancia es un constituyente vital de la sangre y otros fluidos corporales, por lo cual es necesario su consumo periódico (Andrews, 1983: 8; McKillop, 2018: 265; Williams, 2010). El cuerpo humano requiere que la concentración de sodio en la sangre sea constante y es debido a esto que el sistema endocrino regula su expulsión del cuerpo a través de la orina o el sudor, y su exceso en la sangre produce sed (Andrews, 1983: 9).

Aquellas sociedades que basan su alimentación en el consumo de carne y de productos provenientes del mar, no requieren del consumo adicional de sal. Sin embargo, las plantas tienen un muy bajo contenido en sal, por lo que las sociedades agrícolas, tales como las culturas que se desarrollaron en Mesoamérica, deben complementar su dieta con sal en grano (Williams, 2010; McKillop, 2018: 265). La ausencia de sal en el organismo puede llevar a una gran pérdida de líquidos y finalmente a la muerte por deshidratación, y ésta es la razón por la cual las personas que están expuestas a ambientes calurosos y húmedos deben ingerir cantidades moderadas de sal para evitar una sudoración excesiva y la consecuen- 
te pérdida de agua del cuerpo (Andrews, 1983: 6). El consumo recomendado diario va de uno a cuatro gramos de sal, pero para sociedades que viven en condiciones similares a las de los mayas del Clásico, este consumo podría ir de los ocho a los 10 gramos y en algunos casos, como cuando se realiza una labor física intensa, podría llegar hasta a los 30 gramos diarios. La investigación etnográfica llevada a cabo en la región maya ha podido corroborar un consumo promedio de nueve gramos por día en Yucatán y Chiapas (Andrews, 1983: 9; Arias, 1972: 74; Redfield y Villa Rojas, 1934: 57), que concuerda muy bien con los 9.2 gramos señalados en estudios recientes que analizan el estroncio presente en los huesos de los pobladores de Tikal (Fenner y Wright 2014).

Tomando como base un consumo de nueve gramos por día y aplicándolo a una población como la de Calakmul, que posiblemente pudo llegar a tener 50,000 habitantes en su momento de mayor tamaño, ${ }^{1}$ el consumo anual de sal sería de alrededor de 165 toneladas. Tales cantidades implican la resolución de cuestiones de tipo logístico y de transporte no obvias para una región como la maya durante el Clásico, sobre todo para aquellos sitios que no producen sal, como lo son la mayoría de los localizados en el Petén. Pero veremos que las fuentes de sal estaban localizadas, si no cerca, sí en regiones próximas a las principales ciudades del Clásico.

La sal se ha empleado para conservar el pescado desde tiempos remotos, pues las civilizaciones tempranas de Mesopotamia ya empleaban este método, así como los pueblos alrededor del Golfo Pérsico, en la costa de Omán y del mar Arábico. El curado de pescados se muestra en pinturas murales de tumbas en Egipto (Figura 2) y era un arte tan estimado que sólo los oficiales del templo conocían el proceso. Es significativo que la palabra para conservar pescado sea la misma que para embalsamar a los muertos (Shepard, 2000: 67).

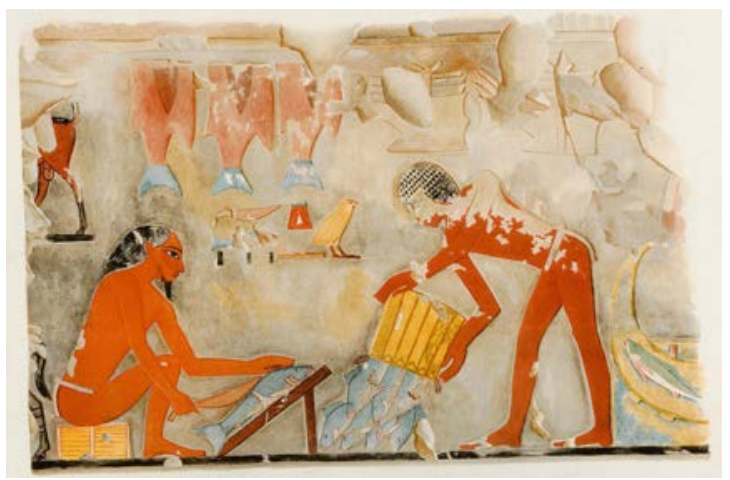

Figura 2. Ilustración de la conservación de pescados con sal en el mural de la tumba de Puy-em-rê, segundo sacerdote de Amún, Egipto, 1450 a.C. (Davis, 1922: Lám. XVII).

1 Algunas de las propuestas poblacionales para Calakmul varían entre 30,000 y 50,000 (ver Braswell et al., 2004: 170; Sharer y Traxler, 2006; Delvendahl, 2008: 17; Rodríguez, 2012: 102), aunque la mayoría de las fuentes reportan 50,000 habitantes. 
La sal pudo ser empleada también en el área maya para preservar el pescado (Williams, 2010: 177), pero se han encontrado pocos restos de peces marinos en sitios arqueológicos tierra adentro, ${ }^{2}$ aunque Landa menciona que esta costumbre se empleaba en el norte de Yucatán (Landa, 1985: 165). Asimismo, la sal fue utilizada en muchas culturas para la realización del proceso de curtido de pieles, pero se desconoce en qué medida los antiguos mayas la emplearon con ese propósito (Williams, 2010: 179).

La sal tenía también un uso ritual, puesto que los mayas se abstenían de tomarla, junto al chile, durante periodos previos a ceremonias, tal y como lo indica Landa (1985: 87). Aún ahora, varias de las salinas localizadas dentro del área maya actúan como centros rituales y son todavía lugares de peregrinación, como las de Atzam en Chiapas, San Mateo Ixtatán y Sacapulas en Guatemala o Emal en Yucatán. Es especialmente llamativa la peregrinación realizada por los tojolabales del oriente de Chiapas, que visitan el pueblo de San Mateo Ixtatán el segundo viernes de cuaresma, antes del inicio de la temporada de lluvias, con el fin de pedir por sus cosechas (Cuadriello y Megchún, 2006: 28). De acuerdo con Ruz (1990, I: 59) la tradición oral tojolabal sitúa sus orígenes étnicos en el sitio arqueológico de K'atepam, vecino a San Mateo Ixtatán, posible motivo de la peregrinación. Según los propios tojolabales, fueron obligados a abandonar la región por conflictos relacionados con las propias salinas. También existe evidencia de que la sal procedente de las tierras altas occidentales de Guatemala fue utilizada como elemento de intercambio (Feldman, 1985: 21-23; Berdan et al., 2013: 101), en la misma forma que el cacao, pero sólo se le empleaba en transacciones que involucraban productos de pequeño valor (Andrews, 1983: 13-14), tal como ocurría en otras partes del mundo (Williams, 2010: 185).

\section{Fuentes prehispánicas para la obtención de sal en el área maya}

Como se ha indicado, la extracción de sal se puede evidenciar a nivel arqueológico por el empleo de ciertos implementos especializados en su manufactura, conocidos como briquetaje, los cuales consistían de cerámica dedicada sólo a este uso y de muy baja calidad. Sobre todo, se puede hallar en sitios donde la sal se obtenía por cocción de la salmuera, como serían aquellos localizados en las Tierras Altas mayas (Smith, 1998: 131; Williams, 2010: 184). Sin embargo, las rutas empleadas para llevarla desde los lugares de extracción a los de consumo son más difíciles de detectar. La sal, obtenida por desecación solar de salmuera en playas, fue el principal recurso que poseía Yucatán para el comercio a larga distancia, por ello se desarrollaron diversas técnicas para su obtención y proce-

\footnotetext{
${ }^{2}$ De acuerdo con Anthony Andrews (comunicación personal, 2019), esto probablemente se debe al proceso de preparar los pescados mayores, ya que éstos se "fileteaban" y se desechaban los huesos y otras partes del pez.
} 
samiento. Las principales regiones donde se obtenía sal se pueden apreciar en el mapa de la Figura 3.

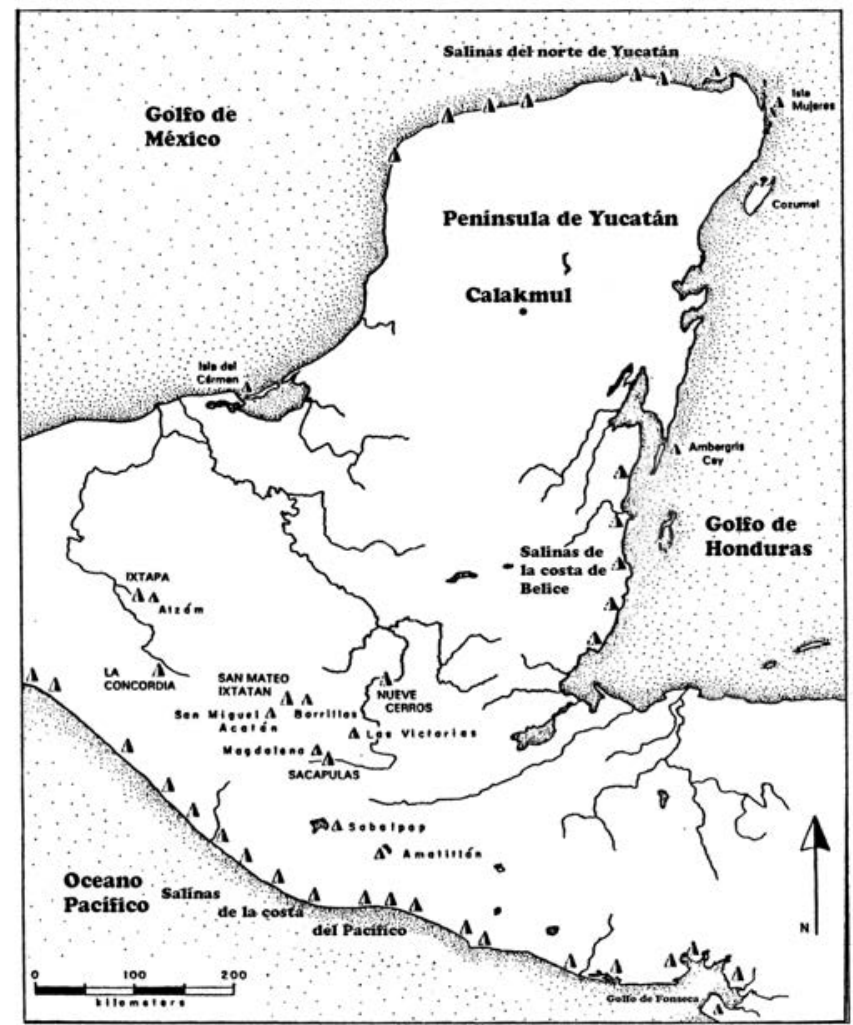

Figura 3. Mapa que muestra la localización de las principales áreas de explotación salinera de la península de Yucatán (cortesía de Anthony Andrews, según Andrews y Mock, 2002: 308, fig. 11.1).

Durante más de 2,000 años se han venido explotando las fuentes de sal del norte de la península. ${ }^{3}$ Varios de los puertos posclásicos estaban localizados en zonas salineras de gran importancia (Andrews, 1978: 86-87; Andrews y Mock, 2002). En el siglo xvı la región surtía a las costas del Golfo hasta Tamaulipas, la costa del Caribe hasta Honduras y también se enviaba al altiplano central. A pesar de haber existido pequeños sitios que producían sal desde el Preclásico en esta zona, como Chikinchel (Kepecs, 1980), se aprecia que, hacia principios del Clásico, se llevó a cabo una centralización de la producción en un grupo reducido de lugares, como Emal, El Cuyo, San Crisanto, Xcambó y La Providencia, los cuales

\footnotetext{
${ }^{3}$ Para una visión general acerca de los sitios prehispánicos relacionados con la explotación de salinas recomiendo el trabajo de Andrews y Mock (2002) y el de McKillop (2018) para las exploraciones más recientes en la región de Belice.
} 
comenzaron a producir sal en cantidades importantes. Muy probablemente la motivación fuera el incremento en la población del Petén, hacia donde iría dirigida la sobreproducción de la zona, pues se han encontrado objetos provenientes de dicha región en la mayoría de ellos (Andrews, 1983: 32). Hacia mediados del Clásico, casi todos siguen produciendo sal, pero algunos lo hacen en mayor cantidad. Estos son San Crisanto, Emal, Xcambó y La Providencia, que cuentan con pequeños complejos de arquitectura monumental. Hacia el Posclásico los sitios de producción de sal migran a los islotes y la desembocadura de ríos y estuarios. Con el auge de Chichén Itzá pasan a estar bajo su control, especialmente Isla Cerritos, que parece fue el principal puerto empleado por esta ciudad (Andrews, 1978; Cobos, 2016).

Cobos (2016) comenta que en Isla Cerritos se han encontrado enterramientos de los que posiblemente eran comerciantes, ya que el ajuar funerario incluía materiales provenientes de diversas regiones de Mesoamérica, lo cual indicaría su importancia como puerto de intercambio. A pesar de que después de la caída de Chichén los puertos costeros fueron abandonados, muchas de las salinas de la costa norte de Yucatán, entre ellas las de Emal, continuaron siendo explotadas durante el Posclásico por poblaciones que vivían en pueblos cerca de la costa. Por ejemplo, las salinas de Xcambó fueron explotadas por gente de Dzemul durante este periodo, y en las listas de tributos de 1549 hay asentamientos en la costa 0 cercanos a ella que pagaban sus tributos en sal, siendo sólo las salinas de la costa de Belice abandonadas durante el Posclásico (Andrews y Mock, 2002). Landa comentaba cómo Mayapán mantenía un control sobre el repartimiento de la sal proveniente de las salinas vecinas a la bahía de Ekab (Landa, 1985: 164). Con la posterior caída de Mayapán, éstas pasaron a estar bajo el control de los grupos provinciales, como los Ah Canul y los Chauaca.

Otra fuente de sal para el aprovisionamiento del área maya la constituyen la cadena de salinas presentes en la zona de los altos de Guatemala y Chiapas, como la de Sacapulas en Guatemala (Reina y Monaghan, 1981). Esta sal se obtiene mediante cocimiento de la salmuera obtenida de manantiales salinos en recipientes de barro. Los principales yacimientos de las tierras altas de Chiapas se localizan en Ixtapa, ${ }^{4}$ Salinas Atzam ${ }^{5}$ y La Concordia, siendo este último el único explotado a gran escala (aunque en la costa había y aún existe una industria salinera bastante extensa). La Concordia era el único sitio del altiplano donde se utilizaba la evaporación solar en lugar de la cocción para obtener la sal, y mantuvo su ocupación desde finales del Preclásico, contando con un pequeño emplazamiento vecino perteneciente al Clásico. Las otras dos salinas tienen un uso básicamente religioso y son lugar de peregrinaje, como la de San Mateo Ixtatán. El objetivo

\footnotetext{
${ }^{4}$ Ixtapa es un vocablo náhuatl que se compone de iztatl, "blanco", atl, "agua”, y pan, "en”, lo que en su conjunto significa "en el agua blanca", es decir, salina. Posiblemente el nombre de San Mateo Ixtatán tenga un origen similar.

${ }^{5}$ Atz'am es la palabra maya para designar a la sal.
} 
de las visitas a estos sitios es mantener contentos a los dioses que hacen que los manantiales produzcan sal (Andrews, 1983: 58).

Existía también otro conjunto de salinas en la costa del Pacífico, que comenzaron a ser explotadas desde finales del Preclásico y continúan hasta la actualidad (Andrews, 1983, 1991; Andrews y Mock, 2002). Sin embargo, la salina más importante localizada en Tierras Bajas es la de Salinas de los Nueve Cerros, o Bolon Te' Huitz en yucateco. Está localizada muy cerca del río Chixoy, en el departamento de Alta Verapaz y se encuentra asociada a un sitio arqueológico del mismo nombre que fue ocupado desde el Preclásico hasta el Clásico Terminal (Dillon, 1977: 51-53; Woodfill et al., 2015). El sitio tiene una filiación clara con el Petén (Thompson, 1970: 126; Dillon, 1977: 52; Woodfill et al., 2015: 174) y según el único monumento con inscripciones pertenecía o estaba afiliado a una dinastía denominada Chan, "Cielo" (Wölfel y Wagner, 2010). Se conoce este lugar por haber sido, de acuerdo con el Chilam Balam de Chumayel (Edmonson, 1986: 57), una de las cuatro capitales fundadas a la caída de Chichen Itzá durante el k'atun 4 ajaw. Curiosamente, el otro nombre que se le da en dicho documento es Can Hek Uitz, siendo Kan la variante yucateca de Chan, aunque hay investigadores que suponen que el nombre designaba a toda la región de los Altos, no sólo a Salinas de los Nueve Cerros (Dillon, 1977: 7). Su importancia, debida sobre todo a la cercanía a la zona nuclear del Petén y por su nivel de producción, deben haberlo convertido en un lugar muy apreciado por los gobiernos vecinos. De hecho, se menciona que fue causa de disputas entre itzáes y lacandones durante la época colonial. Otro aspecto interesante del lugar es que el otro sitio que parece estar afiliado a la dinastía Chan fue Chinkultic, localizado en la región cercana a un grupo importante de salinas (Wölfel y Wagner, 2010). Quizás este grupo dinástico Chan adquirió su poder por el control que ejercía sobre la producción de sal, necesaria para el resto de grupos de la zona.

En fechas más recientes han sido reportadas otras fuentes prehispánicas de sal en las costas de Belice (Andrews, 1997; Andrews y Mock, 2002; McKillop, 2005, 2018; McKillop, Landrum y Landrum, 2017). Se localizaron 42 nuevos sitios arqueológicos donde se realizaba la obtención de sal, actualmente sumergidos, en la costa de la laguna Ycacos, entre los cuales resulta de especial importancia K'ak' Naab, ya que allí se encontró un remo prehispánico de madera (McKillop, 2005: 5632), así como una canoa (McKillop, Sills y Celluci, 2014; McKillop, Landrum y Landrum, 2017), lo cual permite inferir que el comercio de sal contaba con canoas para su distribución, combinando rutas marítimas, fluviales y terrestres.

Una última fuente alternativa de $\mathrm{sal}^{6}{ }^{6}$ la constituye la quema y secado de cierto tipo de palmas. ${ }^{7}$ Esta técnica es empleada por sociedades relativamente peque-

${ }^{6}$ La sal obtenida de este tipo de plantas no es cloruro de sodio, sino cloruro de potasio.

${ }^{7}$ López de Cogolludo (1955: 700) menciona la quema de una palma llamada xocsam, también llamada palma guano, pero en realidad se refiere a dos especies de palma, las cuales se emplean con este fin, la Sabal mayarum (guano, xan, botal, bayal) y la Cryosophila argentia (kun, xocsam, escobo). 
ñas y aisladas, ${ }^{8}$ y hasta hace relativamente poco era utilizada por los lacandones (Andrews, 1983: 20; McKillop, 1996). La obtención de sal mediante este método es muy lenta, la quema dura muchas horas y la cantidad de sal obtenida es poca y de baja calidad, por lo que no se le puede considerar como una posibilidad para el sostenimiento de grandes grupos de población. De hecho, los lacandones abandonaron su uso una vez que entraron en contacto con compañías madereras que les proveían de cloruro de sodio (Andrews, 1983: 20).

\section{Referencias coloniales a la producción y el comercio de sal}

Cuando los españoles llegaron a la zona norte de Yucatán se quedaron muy impresionados por el tamaño y extensión de la industria salinera de la región, como así lo acredita la Relación de Mérida, parte de las Relaciones Histórico-Geográficas de Yucatán (De la Garza, 1983, 1: 274), donde se indica lo siguiente:

Hay en toda la costa de estas provincias muchas salinas, donde naturalmente, sin ninguna industria humana, se cría grandísima cantidad de sal blanca como la nieve y de muy lindo sabor, de lo cual se provee toda esta tierra y es común a indios y españoles, y llévase por mar a otras muchas partes en navíos que vienen a cargar de ello...

La sal resultaba de gran importancia durante la Colonia para el proceso de obtención de la plata (Williams, 2003: 32), de ahí el interés por el registro de sus fuentes de producción. La primera crónica respecto a la industria de obtención de la sal la realiza Landa (1985: 164):

Hay una ciénaga en Yucatán digna de memoria pues tiene más de 70 leguas de largo y es salina toda ella; comienza desde la costa de Ekab, que es cerca de la Isla de Mujeres... Esta ciénaga es salina que Dios ha criado allí de la mejor sal que yo he visto en mi vida, porque molida es muy blanca, y para sal dicen los que lo saben es tan buena.

Otra fuente que menciona la sal en esta región es la de fray Antonio de Ciudad Real (1976, 2: 315):

Casi en toda aquella costa, desde Campeche hasta el Río de Lagartos y más adelante, hay salinas maravillosas, que sin beneficiarlas dan mucha sal, gruesa y muy blanca y de mucho valor, de que se provee toda la provincia, y llevan navíos cargados a la Nueva España, Habana, Honduras y Pánuco y a otras partes; extienden y van prolongadas estas salinas, casi cincuenta leguas por la mesma costa, orilla del mar, y con el agua del cielo, cuando llueve, se cuaja en ellas la sal; acuden a su tiempo españoles e indios, y metidos en el agua amontonan toda la sal que pueden,

${ }^{8}$ Además de los lacandones, se ha documentado su uso por parte de grupos en el Kalahari. 
después la sacan de allí y hacen della grandes montones, a los cuales pegan fuego por encima, con que se hace una costra gruesa y recia, que no se deshace aunque llueva sobre ella días y noches; y si esta diligencia no se hiciese, luego en lloviendo se desharía y se convertiría en agua; de aquellos montones, hecha cargas, la meten la tierra adentro, o la venden a los navíos que acuden por ella.

En la Relación de Motul se indica que era objeto de intercambio, a la altura de las mantas de algodón y el cacao, como la que se muestra a continuación:

Los tratos y las contrataciones y granjerías que hay entre los españoles son mantas de algodón, cera y miel y sal y otras cosas de mantenimiento que venden unos y otros, en cacao que se trae de la provincia de Tabasco y de Honduras; y de la Nueva España se trae un género de mercadería que se llama tuchumite (tochomitl) (De la Garza, 1983, 1: 274).

López de Cogolludo (1955: 528) menciona que los habitantes que vivían cerca de las salinas, pagaban su tributo en sal:

También eran comunes las salinas, que están en las costas de la mar y los moradores cercanos a ellas solían pagar su tribulo a los señores de Mayapán con alguna sal de la que cogían.

Esto indica que el uso de las salinas era comunal y que los pobladores aprovechaban que podían explotarlas con la finalidad de pagar el tributo. Es interesante notar que la sal se empleaba en el área maya durante el Posclásico como producto para el pago de tributos. Asimismo se cuenta con un conjunto de documentos escritos entre 1603 y 1608 denominados las Salinas de Yucatán, en los que se detalla el nombre de cada salina, su ubicación y la producción de cada una.

Otra cosa que impresionó a los españoles del periodo fue la distancia a la que se llegaba a realizar el comercio de la sal. Como indican Ciudad Real (1976, 2: 315) y Landa (1985: 165), esta sal llegaba muy lejos, pues además de los sitios que indica en su relación, se ha encontrado evidencia en documentos ch'oles que apuntan a que penetraba por los afluentes del Usumacinta y el Candelaria para llegar hasta el Petén (Scholes y Roys, 1968: 59).

Las salinas de Ixtapa se encontraban en operación a la llegada de los españoles a esa zona, y son mencionadas por Remesal (1932, II: 178) y Díaz del Castillo, quien además comenta con respecto a los mercaderes que vio en la región de Acalán:

E yendo por la costa del Norte vio que venía por la mar una canoa a remo y a vela, y se estuvo escondido un día en el monte, porque vieron venir por la mar la canoa la cual era de indios mercaderes, y venía costa a costa, y traían mercaderías de sal y maíz, e iban a entrar en el Río Grande del Golfo Dulce (Díaz del Castillo, 1975: 497).

También Tovilla hace referencia al proceso de producción de sal de los pueblos de Sacapulas en Guatemala, mediante la desecación utilizando fuego debajo de tecomates llenos con agua salina, proceso que se sigue llevando a cabo hasta 
nuestros días (Reina y Monaghan, 1981). Se puede apreciar por las fuentes, no siendo las mencionadas las únicas existentes, que el comercio era una práctica habitual a la llegada de los españoles a América, que un medio privilegiado para el transporte de las mercancías fue el fluvial y que la sal fue uno de los principales bienes de intercambio transportado por esta vía. Por último, resulta especialmente interesante la mención que realiza Francisco Hernández a los métodos por los cuales se obtenía la sal, aunque no menciona su obtención a partir del uso de plantas (Barros y Buenrostro, 2007: 146), sino a través de la desecación de agua de mar o de fuentes de agua salada.

\section{La sal en las pinturas murales de Calakmul}

Hasta el descubrimiento de las pinturas murales de la Estructura Sub I-4 del Edificio 1 de la Acrópolis Chi'k Nahb en Calakmul (Carrasco et al., 2005: 137-142; Carrasco, Vázquez y Martin, 2009; Martin, 2012; Carrasco y Cordeiro, 2012), no se tenía constancia epigráfica o iconográfica de la presencia de la sal en el área maya (Boucher y Quiñones, 2007: 47; Carrasco, Vázquez y Martin, 2009; Martin, 2007: 20).

En estos murales se presentan diversas personas portando el título agentivo $a j$, que sirve para indicar el hecho de que una persona se dedica a un determinado oficio o que procede de un lugar en particular (Carrasco, Vázquez y Martin, 2009: 19248; Martin, 2007: 7; Martin, 2012: 62; Zender, 2005). El grupo de personajes se muestra ofreciendo bienes a los que parecen ser cortesanos, identificables por los tocados que portan. La gran mayoría de los elementos ofrecidos son alimentos, entre los que se encuentran una bebida de maíz similar al atole — denominada ul en ch'olano clásico-, tamales — denominados waaj—, tabaco — denominado mahy-, así como bienes utilitarios, tales como vasos cerámicos, entre muchos otros. Ambos grupos se distinguen además por su vestimenta, tal como lo han notado varios investigadores (Boucher y Quiñones, 2007: 49; Martin, 2007: 32).

Un aspecto particularmente interesante de tales imágenes es que algunos miembros del grupo asociado a los agentivos portan sombreros, prendas que suelen estar relacionadas con los comerciantes en Mesoamérica (Tokovinine y Beliaev, 2013: 178). Así mismo, portan pintura corporal, ya que una gran mayoría tienen pintados diseños en los rostros y algunos además llevan diseños de manos pintados sobre el cuerpo, como es el caso de la mujer mostrada en la pintura localizada en el extremo derecho de la esquina SO-S2 ${ }^{9}$ de la estructura Sub I-4 del Edificio 1 de la Acrópolis Chi'k Nahb de Calakmul, la cual lleva pintada una mano sobre el muslo de la pierna visible en la pintura, y que además porta un sombrero (Figura 4).

\footnotetext{
${ }^{9}$ La denominación empleada en este artículo para las escenas de las pinturas de la estructura Sub I-4 del Edificio 1 de la Acrópolis Chi'k Nahb de Calakmul es la definida por Carrasco y Cordeiro (2012: 14). En este caso significaría la esquina suroeste, segundo cuerpo.
} 


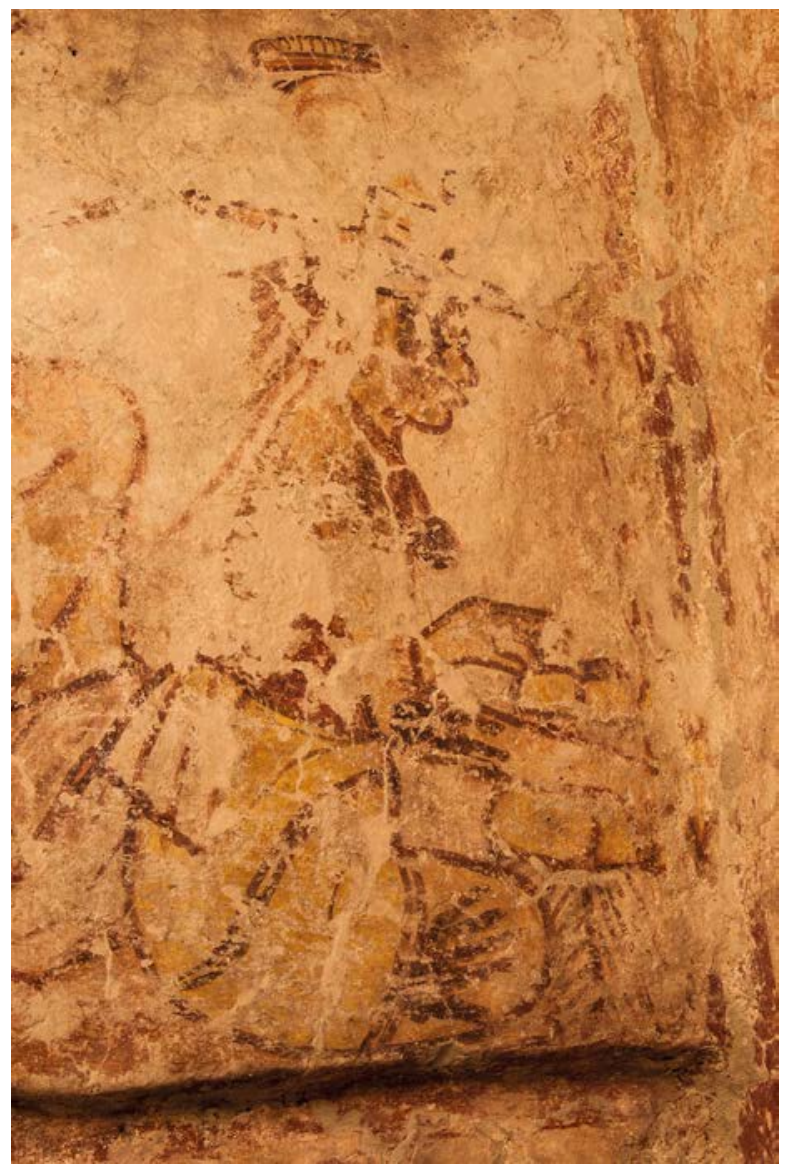

Figura 4. Imagen que muestra a una de las distribuidoras de bienes portando sombrero y con una mano pintada sobre el muslo derecho, localizada en la esquina SO-S2 de la Estructura Sub I-4 del Edificio 1 de la Acrópolis Chi’k Nahb de Calakmul (Cortesía del Proyecto Arqueológico Calakmul. Fotografía: Rogelio Valencia).

La pintura corporal —en este caso las manos pintadas sobre el cuerpo- representa un símbolo de pertenencia a un grupo particular, un mecanismo a través del cual se permitía la comunicación de la identidad social, tanto dentro del grupo como hacia fuera del mismo (Nehammer, 2013: 116-117). Esto nos permite inferir que las personas que han llevado hasta Calakmul y distribuyen los objetos mostrados - alimentos, tabaco, vasijas - pertenecen a un grupo diferente del que los recibe, posibles cortesanos locales y que no son parte de los residentes de la ciudad.

Es una de tales pinturas, en particular, la que resulta importante para analizar la presencia de la sal en Calakamul. En la escena localizada en la esquina NE-E1 se aprecia a un varón, que porta un sombrero, con un cucharón en la mano, si- 
tuado a la izquierda de una canasta, mientras una mujer a la derecha sostiene un recipiente que parece estar hecho de hojas en sus manos (Figura 5).

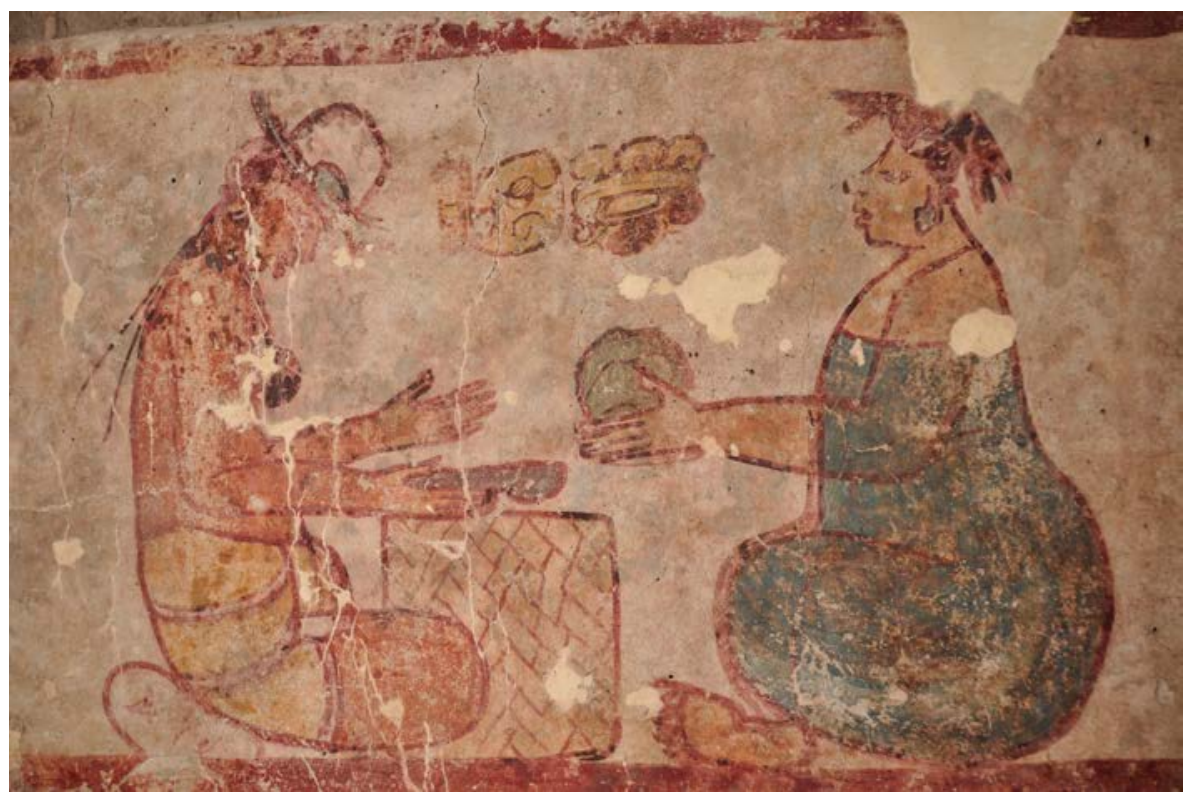

Figura 5. Imagen que muestra al aj atz'aam, "el de la sal”, localizada en la esquina NE-E1 de la Estructura Sub I-4 del Edificio 1 de la Acrópolis Chi'k Nahb de Calakmul (Cortesía del Proyecto Arqueológico Calakmul. Fotografía: Rogelio Valencia).

El texto jeroglífico asociado indica, AJ-a-tz'a-mi, aj 'atz'aam, "la persona de la sal” (Carrasco, Vázquez y Martin, 2009: 19248; Martin, 2012: 68-69). La palabra 'atz'aam posee cognadas en varias lenguas mayas, tal y como se puede apreciar en los siguientes ejemplos: en chol, atsam ${ }^{10}$ (Becerra, 1937: 31); en ch'olti, atsam (Robertson, Law y Haertel, 2010: 346); en chontal, atzám (Pérez, 1985: 101); en huasteco, at'em (Bernardo de Quirós, 2013: 229); en mam, atz'am (Ortiz, Pérez y Hernández, 2001: 11); en quiche, atz'am (Edmonson, 1965: 9); en tzeltal, ats'am (Slocum y Gerdel, 1981: 117), y en tzotzil, 'ats'am (Weathers y Weathers, 1949: 24; García de León, 1971: 39; Hurley y Ruiz, 1986: 360).

Algo que ha causado cierta controversia entre los investigadores es la forma en la que se representa la sal en este mural, pues su presencia en la imagen no es evidente. Las fuentes etnográficas nos indican que la forma usual de transportarla es en canastos hechos de palma, tal y como se puede apreciar en la Figura 1 , en la cual se muestra una salinera que funciona mediante desecación solar, localizada en la reserva de la biósfera de Tehuacán-Cuicatlán, México, y en la que

\footnotetext{
${ }^{10}$ Para las entradas procedentes de diccionarios se mantiene la ortografía original empleada por cada autor.
} 
se pueden apreciar los canastos mediante los cuales la sal es transportada. En la Figura 6 se pueden apreciar los canastos procedentes de otra salinera de la misma región, pero en este caso llenos de sal.

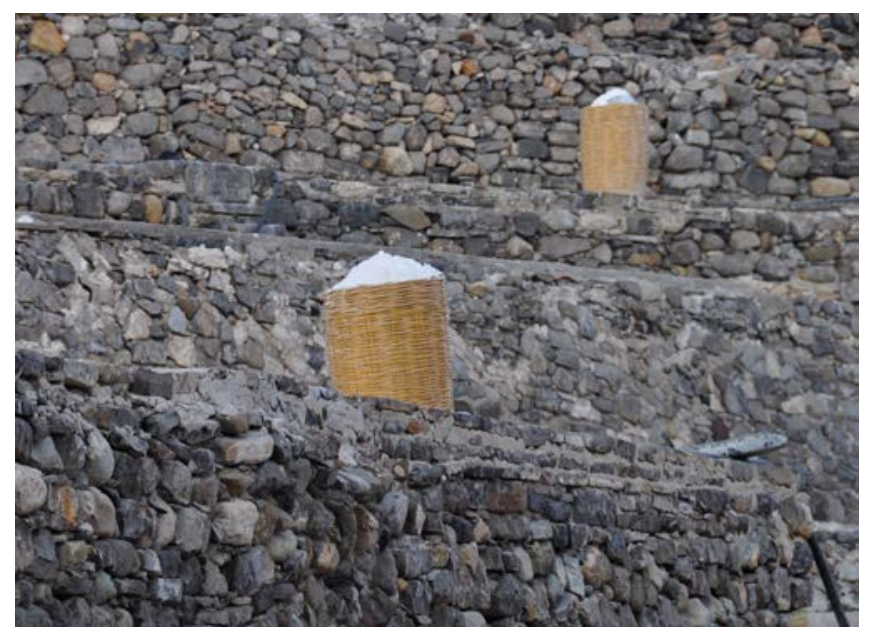

Figura 6. Canastos llenos de sal procedentes de una salina localizada en la reserva de la biósfera de Tehuacán-Cuicatlán (Fotografía: Rogelio Valencia).

Asimismo, la sal podía ser transportada en contenedores elaborados del mismo material vegetal que los canastos para albergar pequeños panes de sal, tal y como se puede apreciar en la Figura 7, que muestra dichos contenedores, llamados "benequenes", procedentes de Ixtapa, Chiapas.

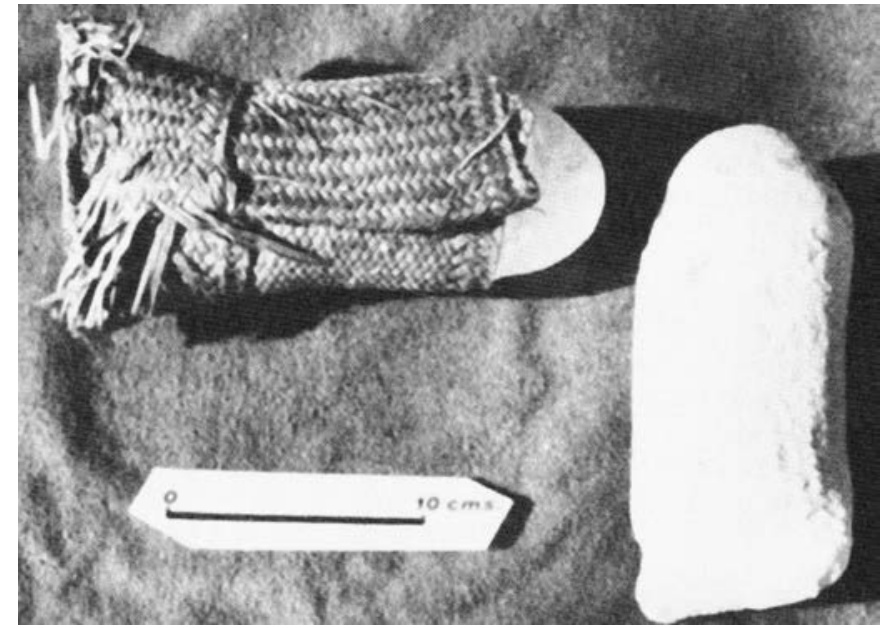

Figura 7. Benequenes hechos de palma para transportar panes de sal. (Cortesía de Anthony Andrews, según Andrews, 1983: 58, fig. 3.6). 
Como se puede apreciar en la pintura de Calakmul (Figura 5), el contenedor principal de la sal está hecho probablemente de palma trenzada al tratarse de un canasto, la misma técnica empleada para los contenedores de sal de TehuacánCuicatlán o para los benequenes utilizados en Chiapas. Además, es muy probable que lo que la señora lleva en las manos sea un contenedor de origen vegetal, como los que se emplean aún en la actualidad en las zonas costeras de México, con el fin de que la sal no se humedezca tanto, ya que la humedad relativa de sitios como Calakmul es muy alta todo el año, lo cual provoca que la sal se apelmace y diluya. También se ha señalado la posibilidad de que se trate de un elemento cerámico con forma vegetal (Martin, 2007: 20), como el que procede de la ciudad maya de Acanceh que representa una calabaza (Figura 8).

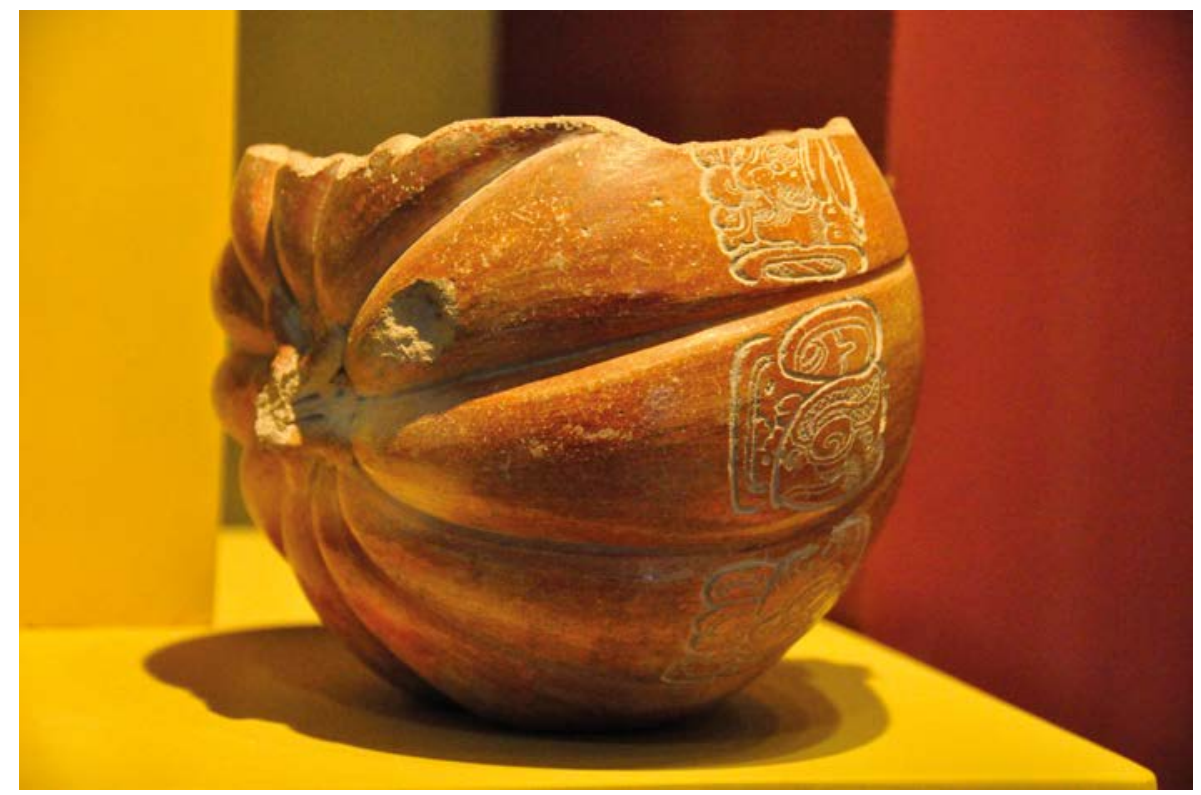

Figura 8. Vasija con forma de calabaza procedente de Acanceh (Fotografía: Rogelio Valencia).

\section{Procedencia de la sal en Calakmul}

No se han encontrado salinas u otras fuentes de sal cercanas a la ciudad de Calakmul y si descartamos la posibilidad de su manufactura local mediante el empleo de palmas o algún otro vegetal debido a la cantidad de sal requerida por la población de Calakmul según los cálculos indicados al inicio de este artículo, lo más lógico es considerar que esta sal provenía de algún lugar donde se producía en suficiente cantidad como para permitir el intercambio de su excedente o su recepción como tributo. Se puede entonces suponer que la sal se traía de lejos y 
para transportarla sería necesaria la presencia de cargadores, el único medio por el cual se trasladaban mercancías por tierra en Mesoamérica (Hirth, 2013: 90); según comenta Ciudad Real, en la Nueva España se carecía de animales de carga, por lo que todo se transportaba mediante el empleo de cargadores humanos:

Animales de carga no los tenían los indios en su antigüedad; ellos mesmos se llevan a cuestas sus cargas, y agora también lo hacen por la mayor parte, y no sólo las suyas, pero también las de los otros, y esto era y es general en toda la Nueva España (Ciudad Real, 1976, 1: 57).

Dentro del conjunto de pinturas contenidas en la Estructura I de la Acrópolis de Chi'k Nahb se ilustran algunos personajes que pueden ser identificados con los que en Mesoamérica se consideraban como cargadores, es decir, personas dedicadas al transporte de mercancías. Allí puede apreciarse a un par de cargadores transportando ollas (Figura 9), como las mostradas para servir bebidas en otras secciones del mural.

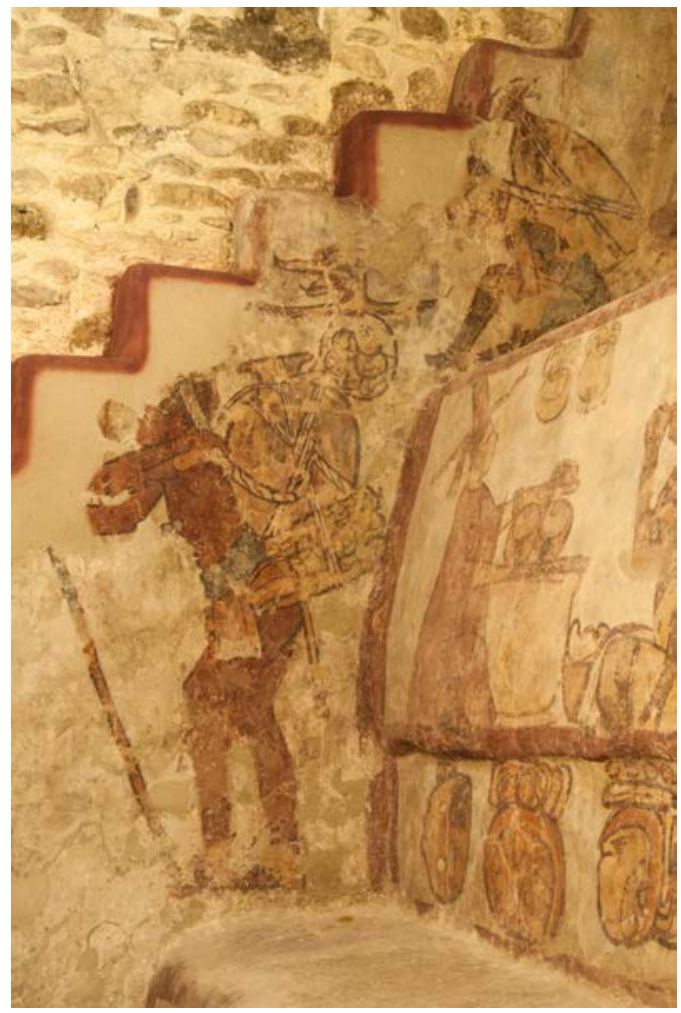

Figura 9. Imagen que muestra a un par de cargadores, localizados en las escenas EsS-LtE2 y EsS-LtE3 de la esquina sureste de la Estructura Sub I-4 del Edificio 1 de la Acrópolis de Chi’k Nahb de Calakmul (Cortesía del Proyecto Arqueológico Calakmul. Fotografía: Rogelio Valencia). 
El cargador que se muestra en la parte inferior del costado de la escalinata central del edificio (EsS-LtE2) lleva un sombrero ${ }^{11}$ de ala ancha adornado con la cabeza de lo que parece ser un mamífero sobre el bastidor con su carga, báculo y sandalias. El sombrero que porta es muy semejante al que aparece junto a la representación del Dios L de Cacaxtla (Martin en Brittenham, 2015: 151), siendo ésta una deidad relacionada con el comercio por su afinidad al cacao (Gillespie y Joyce, 1998; Martin, 2006, 2010; Valencia, 2011, 2018) y por aparecer regularmente junto a fardos de mercancías, una de las cuales probablemente fuera esos mismos sombreros (Beliaev y Davletshin, 2006; Martin, 2013: 535; Martin en Brittenham, 2015: 151).

El báculo y el bastidor con la carga, llamado cacaxtli ${ }^{12}$ entre los nahuas del centro de México, son elementos que aparecen representados junto a los comerciantes en toda Mesoamérica y los identifican (Brittenham, 2015: 156). Especialmente importante era el báculo, pues sabemos que los comerciantes de diversas regiones de Mesoamérica antes de partir a su destino hacían conjuros no sólo al dios de los comerciantes, sino también a los dioses del camino, donde el báculo jugaba un papel destacado. Los mercaderes mexicas, por ejemplo, esperaban a una fecha propicia para iniciar su viaje, y una vez decidida se rapaban la cabeza y se lavaban, pues durante el viaje no volverían a hacer ninguna de tales cosas. A la medianoche de ese día, realizaban una ceremonia en la que ofrecían papeles embadurnados de ulli al dios del fuego, Xiuhtecutli, al dios de la tierra, Tlaltecutli, al dios de los mercaderes, Yacatecutli, Cecoatl Otli Melauac, y a los dioses del camino, Zacatzontli y Tlacotzontli (Johansson, 1983: 35). Quemaban en las brasas los papeles dedicados al dios del fuego y con aquellos dedicados a los dioses del camino y al dios de los mercaderes, cubrían un báculo de caña maciza, el cual conservaban durante todo el camino. Al amanecer se organizaba un convite, que duraba todo el día, y al anochecer partían (Johansson, 1983: 35). Por su parte, Landa menciona la existencia de ceremonias semejantes realizadas por los comerciantes mayas a Ek Chuah, como dios relacionado con los caminantes, equivalente maya a los dioses del camino mexicas:

Y que aun los caminantes llevaban en sus caminos incienso y un platillo en que quemarlo, y así, por la noche; do quiera que llegaban, erigían tres piedras pequeñas y ponían en ellas sendos pocos del incienso y poníanles delante otras tres piedras llanas en las cuales echaban el incienso, rogando al dios que llamaban Ekchuah los volviese con bien a sus casas; y esto lo hacían cada noche hasta ser vueltos a sus casas donde no faltaba quien por ellos hiciese otro tanto y aun mas (Landa, 1985: 88).

\footnotetext{
11 Estos sombreros son muy parecidos a los que portan los tzotziles en la actualidad (Anthony Andrews, comunicación personal, 2019).

${ }^{12}$ Cacaxtli, "escalerillas de tablas para llevar algo a cuestas el tameme, o cierto pájaro“ (Molina, 2013, II: 10).
} 
Ahora bien, la presencia de cargadores en los murales de Calakmul implica que la sal se transportaba desde otros lugares cuya lejanía podría ser variable. De acuerdo con los estudios de Hirth (2013: 93-95), acerca de la procedencia de la sal empleada por diversas comunidades y documentada en la pregunta 30 de las Relaciones Geográficas solicitadas por el rey Felipe II a los pueblos sujetos a la corona española en el año de 1569 de la mano de Juan de Ovando y Godoy (De la Garza, 1983, 1: XII), los nombres de los lugares de origen se restringen a un grupo muy específico de localidades, por lo que parece ser que existían relaciones a largo plazo entre pueblos consumidores y productores de sal. De dicho análisis se desprende que existieron 122 productores de sal mencionados en las Relaciones Geográficas, así como 196 sitios consumidores, por lo que se puede determinar la esfera de influencia de cada productor de sal (Hirth, 2013: 93); los grandes productores de sal llegaban a trasportarla a lugares consumidores que se encontraban entre 175 y $325 \mathrm{~km}$ de distancia (Hirth, 2013: 95). Si tomamos como referencia estas distancias, Calakmul estaría dentro de la esfera de distribución de los grandes productores de sal antes mencionados (Figura 10).

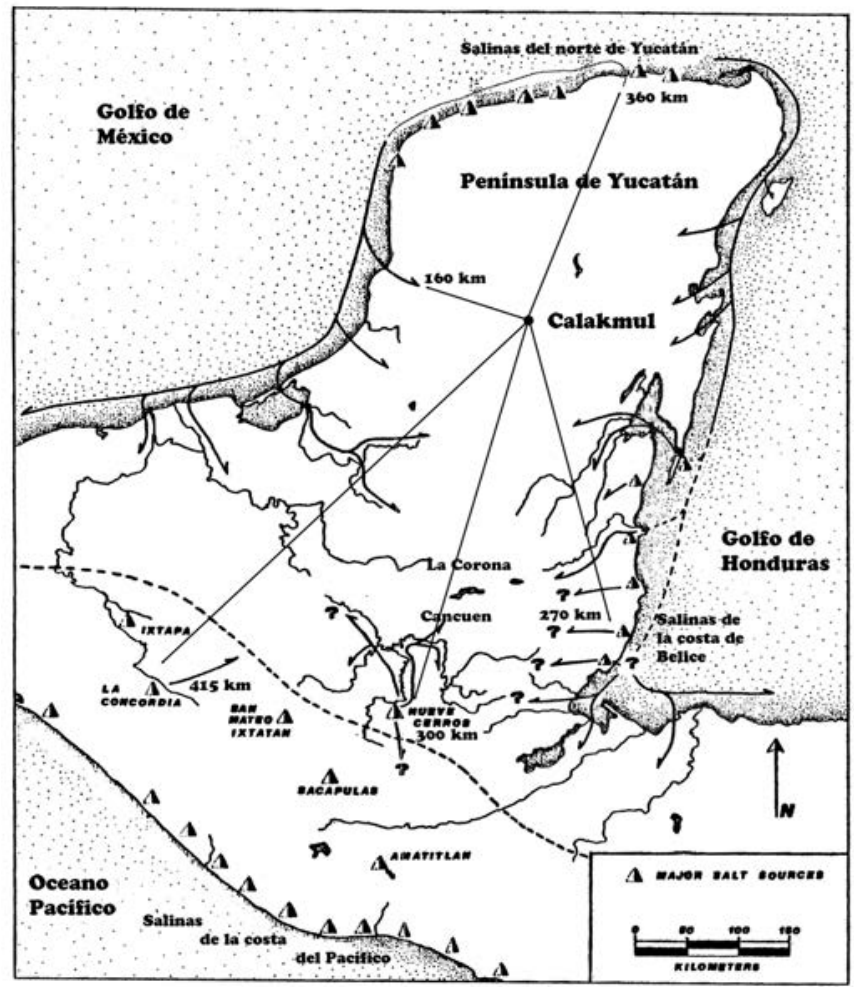

Figura 10. Mapa que muestra la localización de los principales sitios productores de sal de la región maya, indicando la distancia a la la ciudad de Calakmul (Cortesía de Anthony Andrews, según Andrews y Mock, 2002: 324, fig. 11.5). 
La ciudad se encuentra aproximadamente a $270 \mathrm{~km}$ de distancia de los sitios productores cercanos a la laguna Ycacos, en la zona costera de Belice, a 360 $\mathrm{km}$ de los sitios productores de la costa norte de Yucatán, y a unos $300 \mathrm{~km}$ de Bolonte'witz (Salinas de los Nueve Cerros), quedando fuera de este rango las salinas localizadas en Chiapas, a $415 \mathrm{~km}$ de distancia. Desde Salinas de los Nueve Cerros se podía acceder a la ruta comercial que pasaba por Cancuén, lugar especializado en el intercambio de mercancías, como la obsidiana, el jade, la cerámica, las plumas de quetzal y posiblemente la propia sal (Forné, Andrieu y Demarest, 2014: 34); dicha ruta integraba otros sitios importantes para Calakmul, tales como El Perú y La Corona (Canuto y Barrientos, 2013: 3), ambos aliados de Calakmul junto a Cancuén, lo cual favorecería el acceso de Calakmul a esta fuente de sal (Forné, Andrieu y Demarest, 2014: 34; Woodfill et al., 2015: 163). Las fuentes de producción de la costa de Belice son las más cercanas a Calakmul y posiblemente estuvieran bajo la influencia o el control de los grandes sitios de la región, tales como Naranjo o Caracol, siendo este último un aliado de Calakmul durante su relativa hegemonía (Martin y Grube, 2008) y Naranjo un sitio sobre el que Calakmul mantuvo un cierto grado de control durante algunos periodos (Martin y Grube, 2008: 21, 105), por lo que también podrían haber provisto a la ciudad. La presencia de restos de una canoa (McKillop, Sills y Celluci, 2014; McKillop, Landrum y Landrum, 2017) y un remo (McKillop, 2005: 5632) en K'ak' Naab, uno de los principales sitios productores de sal de esta región, que actualmente se encuentra sumergido, sugieren que la sal era comerciada a gran distancia.

Respecto a las salinas del norte de la península de Yucatán, si bien las más lejanas podrían haber empleado el transporte por canoa, medio muy utilizado por los comerciantes para circunnavegar las costas peninsulares hasta Belice y Honduras (McKillop, 2005: 5630; Scholes y Roys, 1968: 316), y para llegar, a través de la costa de Campeche, hasta Champotón, puerto empleado en la ruta hacia Tabasco (Scholes y Roys, 1968: 316) y que se localiza a sólo $160 \mathrm{~km}$ de Calakmul.

Una prueba final de que la sal consumida en Calakmul era transportada por cargadores la podemos encontrar en otra de las pinturas localizada en el tercer cuerpo de la misma Estructura I de la Acrópolis Chi'k Nahb (Figura 11).

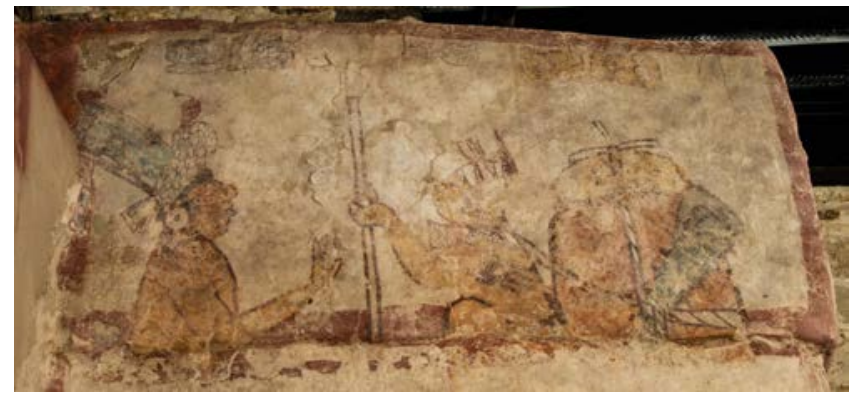

Figura 11. Imagen que muestra a un cargador entregando su carga a un cortesano, localizada en la escena NE-E3 de la esquina noreste de la Estructura Sub I-4 del Edificio 1 de la Acrópolis de Chi’k

Nahb de Calakmul (Cortesía del Proyecto Arqueológico Calakmul. Fotografía: Rogelio Valencia). 
En la imagen se puede apreciar a un cortesano hablando con un cargador, pues se muestran las líneas que conectan los textos de la parte superior de la pintura con la boca de los personajes, representados a modo de bocadillos, como los usados en los comics. El cargador, que lleva una mano pintada en la espalda como marcador grupal, transporta un canasto de gran volumen utilizando un mecapal, ${ }^{13}$ cinta tejida que se apoyaba en la frente, cubierta por una especie de cuenco. Atado al mismo se aprecia lo que parece ser una penca de algún tipo de maguey. Posiblemente se trate de una hoja de henequén (Agave sisalana), planta endémica de la zona norte de la península, lo cual podría ser otra clara indicación de que el cargador procedía de tal región, pues no hay plantas de este tipo en la zona sur de Campeche, donde se localiza Calakmul, ni en la región del Petén. Los textos que aparecen entre ambos personajes son tres y se encuentran localizados en la parte superior de la pintura mural (Figura 12).
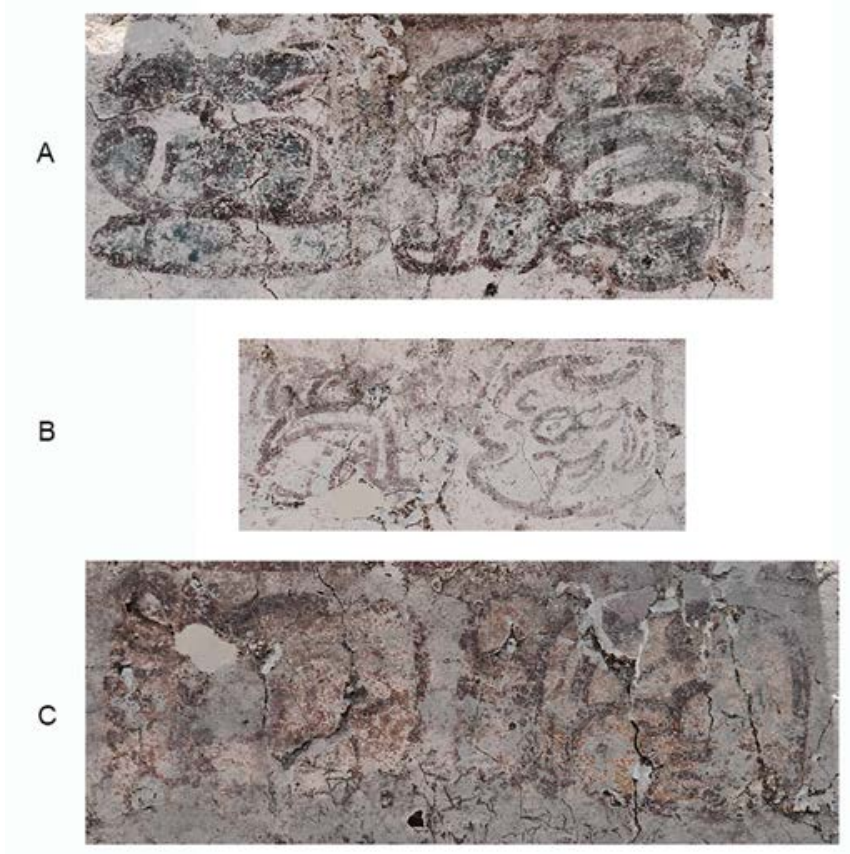

Figura 12. Detalle de los textos que aparecen en la pintura mural localizada en NE-E3. A) k'a-sa-ki a-wa-tz'a-mi, k'asalalk awatz'aam, “... tu sal”. B) hi-\#-ka, hi..ik, “...”. C) AJ-a-tz'a-mi, aj atz'aam, "el de la sal” (Cortesía del Proyecto Arqueológico Calakmul. Fotografía: Rogelio Valencia).

${ }^{13}$ Mecapal procede de la palabra nahuatl mecapalli, "cuerda, correa que sirve para llevar bultos" (Siméon, 1981: 267); “cordel para llevar carga a cuestas" (Molina, 2013: Il-55). Era un artilugio que permitía llevar cargas soportadas por la frente de la persona que las acarreaba, en el caso de la Figura 9 se puede apreciar que la cinta es tejida y que al estar el portador en reposo, ésta descansa sobre su cuello. 
El texto de la izquierda (Figura 12.A) indica lo siguiente, k'a-sa-ki a-wa-tz'a-mi, k'asalajk awatz'aam, “... tu sal”. La primera palabra, k'asaak, podría proceder del verbo k'as, que en tzotzil aparece como k'as, 'quebrar palos o huesos' (García de León, 1971: 54), y también como c'asel, "quebrar” (Hurley y Ruíz, 1986: 31), k’as, "romper, quebrar (algo alargado y rígido: palo, rama, hueso)" (Polian, 2017: 357); otra opción podría ser el verbo k'ases, que significa "pasar, trasladar, transmitir" (Polian, 2017: 357), y que podría tener sentido en este contexto al implicar el intercambio de la mercancía que porta el cargador. ${ }^{14}$ El problema con el empleo del verbo es el sufijo que presenta, $-a a k$, el cual no aparece registrado como un sufijo verbal. Una posibilidad es que la terminación esté relacionada con el sufijo - uk para optativos (Polian, 2017: 60-61), otra opción es que el sufijo fuese -ik, empleado para verbos imperativos transitivos (García de León, 1971: 25), pero esta terminación se emplea con la segunda persona del plural y claramente el hablante se está dirigiendo a una sola persona, esto es, a la segunda persona del singular, lo cual queda perfectamente evidenciado por la segunda palabra: awatz'aam, que se puede analizar morfológicamente como aw-atz'aam, E2S ${ }^{15}$-sal, es decir, emplea el pronombre ergativo de la segunda persona del singular como posesivo para indicar "tu sal". Es decir, la frase indica una orden o una petición por parte de quien la emite para que el cargador divida o pase su sal.

La siguiente frase (Figura 12.B) es la respuesta del cargador que incluye tres sílabas, hi-\#-ka, hi...ik, y cuya lectura podría ser la palabra hiik, ya que la presencia de un segundo signo es imposible de determinar dado el estado de la pintura. Este conjunto jeroglífico debería tener el sentido de una afirmación, considerando el contexto de aparición del mismo, si asumimos que el primer conjunto es una solicitud para dividir el contenido del bastidor de carga del porteador. En todo caso, ambas lecturas son problemáticas. En el último texto (Figura 12.C) aparece de nuevo el agentivo, AJ-a-tz'a-mi, aj atz'aam, "el de la sal”, denominando al responsable de proveer de sal a los cortesanos que aparecen en la pintura, señalando en este caso al personaje que aparece con los atributos del cargador, la cinta para portar la mercancía, el báculo y el fardo con la carga.

\section{Conclusiones}

Se ha discutido mucho acerca de la naturaleza de las imágenes representadas en la pirámide de las pinturas de Calakmul, las distintas teorías apuntan a que se trate de la representación de un día de mercado (Martin, 2007: 32), un banquete ${ }^{16}$

\footnotetext{
${ }^{14}$ Agradezco a Simon Martin su ayuda para la realización de la lectura de este texto jeroglífico (comunicación personal, 2011).

${ }^{15}$ E2S es equivalente a pronombre ergativo de la segunda persona del singular.

16 Existe una posible referencia a festín en las propias pinturas al poder leerse luk'b'aan, donde luk' podría ser tragar (Lacadena comunicación personal, 2010).
} 
(Boucher y Quiñones, 2007: 48), tal vez una entrega de tributo, ${ }^{17}$ o una combinación de varias de estas actividades (Carrasco, Vázquez y Martin, 2009: 19248), como podría ser una celebración en la que asimismo se podrían comercializar o intercambiar productos traídos desde los lugares originarios de los participantes en el acto. Existe evidencia de la realización de tales eventos con más de una finalidad en distintas partes de Mesoamérica en tiempos prehispánicos (Berdan et al., 2013: 101), similares a la actual fiesta del Lunes del Cerro en Oaxaca, comúnmente llamada "Guelaguetza", que además de mercados constituyen una fiesta en la que la comunidad no sólo intercambia sus productos excedentes, sino que al mismo tiempo implica una celebración (Attolini, 2009).

Lo que sí es cierto es que la denominación específica para cada uno de los responsables del control de un producto particular, ya sean vasijas, atole o sal, indica una sociedad especializada y estratificada, así como la distribución de bienes no provenientes de la región circundante (Tokovinine y Beliaev, 2013: 182). El caso de la sal en las pinturas de Calakmul es paradigmático ya que no se cuenta con formas efectivas de producción local, por lo que la sal tendría que proceder de alguna de las fuentes antes mencionadas y ello implica que necesariamente tuvo que ser transportada hacia la ciudad, tal y como lo indica la representación de los cargadores.

Si bien he señalado que la región de procedencia de la sal podría haber sido tanto Belice como Salinas de los Nueve Cerros o las salineras del norte de la península, creo que una ciudad del tamaño de Calakmul no pudo depender de una sola fuente de sal, por lo que posiblemente se surtiera de todas ellas en diferentes épocas. Calakmul, situada temporal y espacialmente dentro de los conflictos bélicos que ocurrieron dentro de la región del Petén durante el Clásico Tardío y que involucraron a sitios importantes de la región central y oriental del área maya, posiblemente diera preferencia a las fuentes situadas lejos de dichos conflictos, es decir las del norte de la península. Entre la poca evidencia que apunta en esa dirección encontramos la presencia, dentro del bulto que lleva el cargador de la sal, de una planta que sólo se encuentra en dicha región.

Además, como ya hemos señalado, la sal formaba parte de un conjunto de productos que se transportaban a través de las rutas comerciales disponibles para los mayas. Uno de esos bienes era el jade, que se producía en la región del Motagua, y se transportaba a Cancuén, ciudad donde había talleres dedicados a su trabajo (Forné, Andrieu y Demarest, 2014), por lo que debería estar presente entre los elementos introducidos empleando la ruta Cancuén-La Corona. Pero no solamente en esa ruta, ya que como lo demuestra el reciente hallazgo de un cincel de jade con empuñadura de madera hallado en el sitio salinero de Ek Way Nal, en Belice (McKillop, 2019: 91-92), este material probablemente formaba parte de las mercancías que pasaban por ahí para integrarse, junto con la sal, dentro de

\footnotetext{
${ }^{17}$ En ninguno de los textos actualmente descubiertos de los murales se hace referencia a la palabra tributo.
} 
los productos a transportar, ya que dicho cincel no tiene signos de uso y parece poco probable que un objeto de lujo fuera empleado en la salinera. Es decir, si la sal procediera de las rutas comerciales del sur de la península, es muy probable que el jade estuviera entre los materiales mostrados en las pinturas, pero esto no es así, ya que dentro de los productos mostrados en los murales de Calakmul ninguno es de jade, lo cual vuelve a apuntar a un lugar de procedencia desde el que no circulan primordialmente ese tipo de productos. La presencia de la sal en las pinturas de Calakmul nos habla de la existencia del intercambio o comercio a larga distancia, que si bien ya había sido evidenciado con bienes suntuarios (Tokovinine y Beliaev, 2013: 174), queda constatado para bienes necesarios, no sólo para los nobles, sino para toda la comunidad.

\section{Agradecimientos}

Quisiera especialmente agradecer a Simon Martin por la discusión acerca del carácter y posible significado de los textos mayas incluidos en este artículo durante una de las múltiples estancias que realizamos en el sitio arqueológico de Calakmul. También quisiera expresar mi agradecimiento al arqueólogo Ramón Carrasco Vargas, director del Proyecto Arqueológico Calakmul, por haber leído una versión preliminar de este articulo y compartir sus opiniones respecto al mismo, así como por haber autorizado el uso de las imágenes. De igual forma, deseo agradecer a Anthony Andrews sus valiosos comentarios y sugerencias, y por haberme permitido emplear sus ilustraciones para este trabajo.

\section{Bibliografía}

Andrews, Anthony P.

1978 "Puertos costeros del Posclásico Temprano en el norte de Yucatán", Estudios de Cultura Maya, XI: 75-93. DOI: https://doi.org/10.19130/iifl.ecm1978.11.507.

1983 Maya Salt Production and Trade. Tucson: The University of Arizona Press.

1991 "Las salinas del El Salvador: bosquejo histórico, etnográfico y arqueológico", Mesoamérica, 21: 71-93.

1997 “La sal entre los antiguos mayas”, Arqueología Mexicana, 28: 38-45.

Andrews, Anthony P. y Shirley B. Mock

2002 "New Perspectives on the Maya Salt Trade", Ancient Maya Political Economies, pp. 96-108, Marilyn A. Masson y David A. Freidel (eds.). Walnut Creek: Altamira Press.

Arias García, Juan Jesús

1972 "El grupo doméstico en una localidad henequenera de Yucatán", tesis de doctorado en Antropología. México: Escuela Nacional de Antropología e Historia. 
Attolini Lecón, Amalia

2009 "Intercambio y caminos en el mundo maya prehispánico", Caminos y mercados de México, pp. 51-78, Janet Long y Amalia Attolini (coords.). México: Universidad Nacional Autónoma de México, Instituto de Investigaciones Históricas, Instituto Nacional de Antropología e Historia.

Barros, Cristina y Marco Buenrostro

2007 La alimentación de los antiguos mexicanos en la Historia Natural de la Nueva España de Francisco Hernández. México: Universidad Nacional Autónoma de México.

Becerra, Marcos E.

1937 Vocabulario de la lengua chol. México: Secretaría de Educación Pública.

Beliaev, Dmitri y Albert Davletshin

2006 "Los sujetos novelísticos y las palabras obscenas: los mitos, los cuentos y las anécdotas en los textos mayas sobre la cerámica del período Clásico", Sacred Books, Sacred Languages: Two Thousand Years of Ritual and Religious Maya Literature, Acta Mesoamericana 14, pp. 21-44, Rogelio Valencia y Geneviéve Le Fort (eds.). Markt Schwaben: Verlag Anton Saurwein.

Berdan, Frances F., Marilyn A. Mason, Janine Gasco y Michael Smith

2013 "An International Economy”, The Postclassic Mesoamerican World, pp. 96-108, Michael E. Smith y Frances F. Berdan (eds.). Salt Lake City: The University of Utah Press.

Bernardo de Quirós, Seberino

2013 Arte y vocabulario del idioma huasteco (1711), Bernhard Hurch (ed.). México: Bonilla Artigas Editores.

Boucher, Sylviane y Lucía Quiñones

2007 "Entre mercados, ferias y festines: los murales de la Sub 1-4 de Chiik Nahb', Calakmul”, Mayab, 19: 27-50.

Brasswell, Geoffrey E., Joel D. Gunn, María del Rosario Domínguez, William J. Folan, Laraine

A. Fletcher, Abel Morales y Michael D. Glascock

2004 "Defining the Terminal Classic at Calakmul, Campeche", The Terminal Classic in the Maya Lowlands: Collapse, Transition, and Transformation, pp. 162-194, Arthur A. Demarest, Prudence M. Rice y Don S. Rice (eds.). Boulder: University of Colorado Press.

Brittenham, Claudia

2015 The Murals of Cacaxtla. The Power of Painting in Ancient Central Mexico. Austin: University of Texas Press.

Canuto, Marcello A. y Tomás Barrientos

2013 "The Importance of La Corona”, La Corona Notes, 1 (1), Mesoweb <www. mesoweb.com/LaCorona/LaCoronaNotes01.pdf> [consultado el 8 de septiembre del 2019]. 
Carrasco Vargas, Ramón, Marinés Colón, Amalia Enríquez, Andreé Bojalil, Sylvianne Boucher, Yoli Palomo, María Pose, Adela Vázquez, Eva Castillo, Cintia Cernadas, Dolores Lores, Alejandra Del Pino, Vera Tiesler, Patricia Quintana y Ana Bertha Canto

2005 Informe técnico temporada 2004, Proyecto Arqueológico Calakmul. México: Instituto Nacional de Antropología e Historia.

Carrasco Vargas, Ramón, Verónica Vázquez López y Simon Martin

2009 "Daily Life of the Ancient Maya Recorded on Murals at Calakmul, Mexico", Proceedings of the National Academy of Sciences, 106 (46): 19245-19249. DOI: https://doi.org/10.1073/pnas.0904374106.

Carrasco Vargas, Ramón y María Cordeiro Baqueiro

2012 "The Murals of Chiik Nahb Structure Sub1-4, Calakmul, Mexico", Maya Archaeology, 2: 60-81, Charles Golden, Stephen Houston y Joel Skidmore (eds.). San Francisco: Precolumbia Mesoweb Press.

Ciudad Real, Antonio de

1976 Tratado curioso y docto de las grandezas de la Nueva España. México: Universidad Nacional Autónoma de México.

Cobos, Rafael

2016 "Belizean Trans-Shipment Maritime Ports: Their Role in Chichen Itza's Economy", Research Reports on Belizean Archaeology, Volume 13, pp. 329-335, John Morris, Melissa Badillo, Sylvia Batty y George Thompson (eds.). Belmopan: Institute of Archaeology, National Institute of Culture and History.

Cuadriello Olivos, Hadlyyn y Rodrigo Megchún Rivera

2006 Tojolabales. México: Comisión Nacional para el Desarrollo de los Pueblos Indígenas.

Davis, Norman de Garis

1922 The Tomb of Puyemrê at Thebes (Band 1): The Hall of Memories. Nueva York: The Metropolitan Museum (Publications of the Metropolitan Museum of Art Egyptian Expedition, Robb de Peyster Tytus Memorial Series 2).

Delvendahl, Kai

2008 Calakmul in Sight. Mérida: Unas Letras, Industria Editorial.

Díaz del Castillo, Bernal

1975 Historia verdadera de la conquista de la Nueva España. Madrid: Espasa-Calpe.

Dillon, Brian D.

1977 Salinas de los Nueve Cerros, Guatemala. Preliminary Archaeological Investigations. Socorro, Nuevo México: Ballena Press.

Edmonson, Munro S.

1965 Quiche-English Dictionary. Nueva Orleans: Tulane University (Middle American Research Institute, Publication 30). 
Edmonson, Munro S.

1986 Heaven Born Merida and its Destiny. The Book of Chilam Balam of Chumayel. Austin: University of Texas Press.

Feldman, Lawrence $\mathrm{H}$.

1985 A Tumpline Economy: Production and Distribution Systems in Sixteeth-Century Eastern Guatemala. Culver City: Labyrinthos.

Fenner, Jack y Lori Wright

2014 "Revisiting the Strontium Contribution of Sea Salt in the Human Diet", Journal of Archaeological Science, 44: 99-103. DOI: https://doi.org/10.1016/j. jas.2014.01.020.

Forné, Mélanie, Chloé Andrieu y Arthur Demarest

2014 "Las actividades económicas como parte de una estrategia política: el caso de Cancuén, una ciudad entre las Tierras Altas y las Tierras Bajas en el Clásico Tardío", Socio-Political Strategies among the Maya from the Classic Period to the Present, pp. 33-50, Verónica Vázquez, Rogelio Valencia y Eugenia Gutiérrez (eds.). Oxford: BAR International Series.

García de León, Antonio

1971 Los elementos del tzotzil colonial y moderno. México: Universidad Nacional Autónoma de México, Instituto de Investigaciones Filológicas, Centro de Estudios Mayas (Serie Cuadernos, 7).

Garza, Mercedes de la (coord.)

1983 Relaciones Histórico-Geográficas de la Gobernación de Yucatán (Mérida, Valladolid y Tabasco). México: Universidad Nacional Autónoma de México, Instituto de Investigaciones Filológicas, Centro de Estudios Mayas.

Gillespie, Susan D. y Rosemary A. Joyce

1998 "Deity Relationships in Mesoamerican Cosmologies", Ancient Mesoamerica, 9: 279-296.

Hirth, Kenneth G.

2013 "The Merchant's World: Commercial Diversity and the Economics of Interregional Exchange in Highland Mesoamerica”, Merchants, Markets, and Exchange in the Pre-Columbian World, pp. 85-112, Kenneth G. Hirth y Joanne Pillsbury (eds.). Washington: Dumbarton Oaks.

Hurley, Alfa y Agustín Ruiz Sánchez

1986 Diccionario tzotzil de San Andrés con variaciones dialectales. México: Instituto Linguí́stico de Verano.

Johansson, Patrick

1983 Teatro Mexicano, historia y dramaturgia. I Festejos, ritos propiciatorios y rituales prehispánicos. México: Consejo Nacional para la Cultura y las Artes. 
Kepecs, Susan M.

1980 Preliminary Report on the Chikinchel Survey Project to the Instituto Nacional de Antropología e Historia, México City, and the Centro Regional de Yucatán, Mérida, ms.

Landa, Diego de

1985 Relación de las cosas de Yucatán. M. Rivera (ed.). Madrid: Historia 16.

López de Cogolludo, Diego

1955 Historia de Yucatán. Campeche: Talleres Gráficos del Gobierno Constitucional del Estado, Comisión de Historia.

Martin, Simon

2006 "Cacao in Ancient Maya Religion: First Fruit from the Maize Tree and Other Tales from the Underworld", Chocolate in Mesoamerica: A Cultural History of Cacao, pp. 154-183, Cameron L. McNeil (ed.). Gainsville: University Press of Florida.

2007 Un informe provisional sobre los murales de la estructura 1 del acrópolis de Chiik Nahb. Proyecto Arqueológico de Calakmul. México: Instituto Nacional de Antropología e Historia.

2010 "The Dark Lord of the Maya Trade", Fiery Pool: The Maya and the Mythic Sea, pp. 160-162, Daniel Finamore y Stephen D. Houston (eds.). New Heaven y Londres: Yale University Press.

2012 "Hieroglyphs from the Painted Pyramid: The Epigraphy of Chiik Nahb Structure Sub1-4, Calakmul, Mexico", Maya Archaeology, 2: 60-81, Charles Golden, Stephen Houston y Joel Skidmore (eds.). San Francisco: Precolumbia Mesoweb Press.

2013 "El Templo Rojo y los mayas: arte, mitología y contactos culturales en las pinturas de Cacaxtla”, La Pintura Mural Prehispánica en México, V: Cacaxtla, Tomo III: Estudios, pp. 529-545, María Teresa Uriarte y Fernanda Salazar (eds.). México: Universidad Nacional Autónoma de México, Instituto de Investigaciones Estéticas.

Martin, Simon y Nikolai Grube

2008 Chronicle of the Maya Kings and Queens. Deciphering the Dynasties of the Ancient Maya. Londres: Thames \& Hudson.

McKillop, Heather

1996 "Prehistoric Maya Use of Native Palms: Archaeobotanical and Ethnobotanical Evidence", The Managed Mosaic: Ancient Maya Agriculture and Resource Use, pp. 278-294, Scott L. Fedick (ed.). Salt Lake City: University of Utah Press.

2005 "Finds in Belize Document Late Classic Maya Salt Making and Canoe Transport", Proceedings of the National Academy of Sciences, 102 (15): 5630-5634. DOI: https://doi.org/10.1073/pnas.0408485102.

2018 "Contingent Multi-Crafting, Surplus Household Production, and the Quest for Maya Salt", Research Reports in Belizean Archaeology, 15: 265-273.

2019 "Unique Jadeite Tool Discovered in Ek Way Nal, Southern Belize", Mexicon, XLI (4): 91-92. 
McKillop, Heather, E. Cory Sills y Vincent Celluci

2014 "The Ancient Maya Canoe Paddle and the Canoe from Paynes Creek Park, Belize", Research Reports in Belizean Archaeology, 11: 297-306.

McKillop, Heather Thomas Landrum y Lillian Landrum

2017 "Diving Deeper in Punta Ycacos Lagoon at the Paynes Creek Salt Works, Belize", Research Reports in Belizean Archaeology, 14: 279-288.

Molina, fray Alfonso de

2013 Vocabulario en lengua mexicana. Castellana/mexicana. Mexicana/castellana. México: Editorial Porrúa.

Nehammer Knub, Julie

2013 "Earning Your Stripes: An Iconographic Analysis of War Paint among Mesoamerican Cultures", The Maya in a Mesoamerican Context: Comparative Approaches to Maya Studies, pp. 93-121, Jesper Nielsen y Christophe Helmke (eds.). Markt Schwaben: Verlag Anton Saurwein.

Ortiz Domingo, Juan, Francisco Pérez Mendoza y Miguel Hernández Mendoza 2001 Diccionario mam. Guatemala: Cholsamaj.

Outram, Alan K.

2007 "Hunter-Gatherers and the First Farmers", Food. The History of Taste, pp. 3561, Paul Freedman (ed.). Londres y California: University of California Press y Thames \& Hudson.

Pérez González, Benjamín

1985 El chontal de Tucta. Villahermosa: Gobierno del Estado de Tabasco.

Polian, Gilles

2017 Diccionario multidialectal del tseltal. Recurso Electrónico: $<$ https://tseltaltokal. org/wp-content/uploads/2018/09/Polian_Diccionario-multidialectal-del-tseltal-enero2015-2.pdf $>$ [consultado el 8 de septiembre de 2019].

Redfield, Robert y Alfonso Villa Rojas

1934 Chan Kom. A Maya Village. Washington: Carnegie Institution of Washington (Publication 448).

Reina, Rubén y John Monaghan

1981 "The Ways of the Maya”, Expedition, 23 (3): 13-33.

Remesal, Antonio de

1932 Historia General de las Indias Occidentales y Particular de la Gobernación de Chiapa y Guatemala. Guatemala: Sociedad de Geografía e Historia (Biblioteca Goathemala).

Robertson, John S., Danny Law y Robbie A. Haertel

2010 Colonial Ch'olti'. The Seventeenth Century Morán Manuscript. Oklahoma: University of Oklahoma Press. 
Rodríguez Campero, Omar

2012 "Urbanismo", Calakmul, patrimonio de la humanidad, pp. 99-113, Campeche: Secretaría de Cultura.

Ruz Sosa, Mario Humberto

1990 Los Legítimos Hombres. Aproximación antropológica al grupo tojolabal. México: Universidad Nacional Autónoma de México, Instituto de Investigaciones Filológicas, Centro de Estudios Mayas.

Santley, Robert S.

2004 "'Prehistoric Salt Production at El Salado, Veracruz, Mexico", Latin American Antiquity, 15 (2): 199-221. DOI: https://doi.org/10.2307/4141554.

Scholes, France V. y Ralph L. Roys

1968 The Maya Chontal Indians of Acalan-Tixchel. Washington: Carnegie Institution of Washington (Publication 560).

Sharer, Robert J. y Loa P. Traxler.

2006 The Ancient Maya. Stanford: Stanford University Press.

Shepard, Sue

2000 Pickled, Potted and Canned. The Story of Food Preserving. Londres: Headline Book Publishing.

Siméon, Rémi

1981 Diccionario de la lengua náhuatl o mexicana, redactado según los documentos impresos y manuscritos más auténticos y precedido de una introducción. México: Siglo XXI Editores.

Slocum, Marianna C. y Florencia L. Gerdel

1981 Vocabulario tzeltal de Bachajón. México: Instituto Linguiístico de Verano.

Smith, Michael

1998 The Aztecs. Londres: Blackwell.

Thompson, Eric S.

1970 Maya History \& Religion. Norman: University of Oklahoma Press.

Tokovinine, Alexander y Dmitri Beliaev

2013 "People of the Road: Traders and Travelers in Ancient Maya Words and Images", Merchants, Markets, and Exchange in the Pre-Columbian World, pp. 169200, Kenneth G. Hirth y Joanne Pillsbury (eds.). Washington: Dumbarton Oaks.

Valencia Rivera, Rogelio

2011 "La abundancia y el poder real: el dios K'awiil en el Posclásico”, Encuentros 2010. De Dioses y de hombres, creencias y rituales mesoamericanos y sus supervi- 
vencias. Volumen V, pp. 67-96, Katarzyna Mikulska-Dąbrowska y José Contel (eds.). Varsovia: Museo de Historia del Movimiento Popular Polaco.

"Maíz y atole son su trono: K'awiil y la Montaña del Sustento", Maya Cosmology. Terrestrial and Celestial Landscapes, pp. 143-158, Milan Kováč, Harri Kettunen y Guido Krempel (eds.). Markt Schwaben: Verlag Anton Saurwein.

Weathers, Kenneth y Nadine Weathers

1949 Diccionario español-tzotzil y tzotzil-español. México: Instituto Lingüístico de Verano.

Williams, Eduardo

2003 La sal de la tierra. Etnoarqueología de la producción salinera en el occidente de México. Jalisco: El Colegio de Michoacán, Secretaría de Cultura del Estado de Jalisco.

2010 "Salt Production and Trade in Ancient Mesoamerica", Pre-Columbian Foodways: Interdisciplinary Approaches to Food, Culture, and Markets in Ancient Mesoamerica, pp. 175-190, E. Staller y M.D. Carrasco (eds.). Nueva York: SpringerVerlag.

Wölfel, Ulrich y Elisabeth Wagner

2010 "The Realm of the Chan Ajaw, An Ancient Maya Kingdom on the Piedmont of the Northwestern Maya Highlands", $15^{a}$ Conferencia Maya Europea, Simposio Internacional Sociedad y Organización Socio-Territorial Maya, Madrid.

Woodfill, Brent K. S., Brian Dervin Dillon, Marc Wolf, Carlos Avendaño y Ronald Canter 2015 "Salinas de los Nueve Cerros, Guatemala: A Major Economic Center in the Southern Maya Lowlands", Latin American Antiquity, 26 (2): 162-179.

Zender, Marc Uwe

2005 "'Flaming Akbal' and the Glyphic Representation of the aj- Agentive". PARI Journal, V (3): 8-10.

Rogelio Valencia Rivera. Mexicano. Maestro en Ciencias por la Universidad Politécnica de Madrid y doctor en Historia con especialidad en Antropología Americana por la Facultad de Geografía e Historia de la Universidad Complutense de Madrid. Especializado en epigrafía, iconografía, historia y religión mayas y mesoamericanas, con énfasis en el análisis de la relación entre texto e imagen en las representaciones plásticas prehispánicas. Forma parte del Proyecto Arqueológico Calakmul desde 2008. Entre sus últimas publicaciones se encuentran "K'awiil y el calendario de 819 días", "Maíz y atole son su trono: K’awiil y la Montaña del Sustento" e "In the Place of the Mist: Analysing a Maya Myth from a Mesoamerican Perspective”, este último en coautoría.

rogelio.valencia.rivera@gmail.com 